\title{
Um Symposium
}

\section{Problemas Administrativos da Diplomacia de Objetivos Móltiplos}

\author{
HERBERT EMMERICH \\ Editor do Simpósio \\ Fonte: Public Administration Review (Nov/Dez/1969) \\ Tradução de Marcos Henrique Côrtes
}

\section{COMPLEXIDADES DA ADMINISTRAÇAOO DA DIPLOMACIA}

Os Estados Unidos enfrentam uma extraordinária rede de complexidade na administraçăo de seus sistemas de diplomacia de objetivos múltiplos espalhados pelo mundo. Ainda que se tenham aspiraçöes modestas em relafão à possibilidade, e mesmo à conVenlência, de obter um grau absoluto de coerência dos vastos e variados programas que exportamos, quando nos confrontamos com outros governos a povos, torna-se indispensável um alto indice de propósitos nitidamente coordenados. Deve-se esperar O tolerar uma ampla variedade de sons produzidos pelos muitos instrumentos especializados que compõem uma orquestra democrática de poder, porém eles devem, de alguma forma, produZir música que esteja em harmonia $\mathrm{com}$ os principais temas de nossos objetivos. Eles devem, pelo menos, não ser tão dissonantes a ponto de acarretar o perigo de se abafarem uns aos outros ou de soar como arranhōes que não convencem nos rádios de outros povos, nos fones de ouvido em reuniozes internacionais ou nas televisōes do pessoal de casa. Algo está errado se, segundo se diz, as instruçōes para um funcionário britânico que chega a Washington incluem a advertência de que ele não se deve deixar abater pelas primeiras repulsas em nossas repartições governamentais, e sim continuar procurando até encontrar uma entidade receptiva.

O objetivo deste prólogo ao simpósio consiste, em suma, em identificar um certo número de complexidades principais da administração da diplomacia. Relacionei deliberadamente uma grande quantidade de obras de referêncla para o leitor que deseje ir mais longe e chamo especialmente 
atenção para a excelente série de ensaios sobre assuntos correlatos publicada recentemente nos "Anais" da Academia Americana de Ciência Politica e Social, sob o título geral de "Recursos e Necessidades da Diplomacia Americana". 1

\section{EFEITOS ADMINISTRATIVOS DA} ERA DA CRISE CRÔNICA

O núcleo básico da complexidade de nossas diretrizes e operações de política externa se situa, evidentemente, no ambiente internacional contemporâneo e nas atuações variáveis e onerosas que os Estados Unidos têm sido obrigados a desenvolver nesse ambiente. Num periodo de conflito que é basicamente ideológico, nós somos os porta-vozes dos conceitos ocidentais de democracia: governo independente, autodeterminação e a primazia do Direito; sistema descentralizado de tomada de decisões com um máximo de propriedade privada e de iniciativa e mobilidade individuais; e liberdade de pensamento, de expressão, de imprensa e da pessoa humana. $O$ próprio pluralismo que nós defendemos nos impede, mesmo que o desejássemos, de enfrentar o mundo com atividades simplistas e monoliticas em que se eximem nossos adversários. Estamos competindo não só pela opinião favorável da humanidade mas também pela adesão de outras nações à nossa posição, contra um oponente capaz e decidido, altamente organizado, como a recente intervenção soviética na Tcheco-Eslováquia nos fez mais uma vez recordar de forma ni-
tida.

Nessa competição perseguimos múltiplos objetivos, visando incrementar nosso próprio comércio e nossos investimentos no exterior, tentando, ao mesmo tempo, prestar assistência a outros países através de programas bilaterais de ajuda, empréstimos e cooperação técnica. Simultaneamente, somos o principal contribuinte para programas multilaterais de assistência a esses paises. Enquanto mantemos um enorme dispositivo militar, com bases espalhadas pelo mundo, dentro de muitos acordos bilaterais e regionais, somos nas Nações Unidas um ativo defensor de um sistema internacional de manutenção da paz e obediência ao Direito. Nossas diretrizes de politica interna e externa estão inseparavelmente entrelaçadas. $O$ dólar tornou-se moeda internacional em muitas terras, cuja prosperidade depende das medidas que adotemos para sustar a inflação em nosso País. A política externa americana é, como desconfio tenha sido durante toda nossa História, uma complicada mescla de altruísmo e interesse nacional. Ela está profundamente impregnada com o que o Professor Cottam chamou de "interferência competitiva" em relação às potências comunistas. 2

- que outrora se conhecia como tempo de paz transformou-se na era da crise crônica, com a suprema ameaça de um holocausto nuclear pairando qual espada de Dâmocles sobre o planeta. Uma série de conflitos multas vezes imprevisiveis, sob a forma de novos tipos de agressão, açöes de guerrilha e de pirataria, e guerras năo

impson, Editor Especial, "Resour1. Smith Simpson, Editor Especial, "cy", uma
ces and Needs of American Diplomacy série de dezoito ensaios em The Annasocial the American Academy of-Political and

Science, Vol. 380 (Novembro de 1968).

2. Richard W. Cottam, Competitive Inter (Unirence and Twentieth Century Diplomacy 1967 ). versity of Pittsburg Press, Pittsburg, 1967). 
declaradas continua a sobrecarregar nossos mecanismos de formulação de diretrizes e nossa capacidade operacional e, na verdade, nossos recursos nacionais frente a necessidades internas urgentes. Em decorrência desses múltiplos fatores, sobre os quais temos um controle limitado, é praticamente impossivel traçar planos de longo prazo rigidos e simples, bem como coordenar com precisão nossos programas multifacetados no exterior.

Essas novas responsabilidades mudaram drasticamente nossa máquina de governo. Assumimos alguns dos aspectos do "estado-quartel" previstos por Harold D. Lasswell." 3 O Orçamento Johnson para o ano fiscal de 1970 previa despesas sob a rubrica defesa nacional no valor de 81,5 biIhões de dólares, dos quais 25,4 bilhöes se destinavam ao Vietnã, representando $42 \%$ de um orçamento global de 195,3 bilhöes de dólares. Comunidades inteiras vivem na dependência de contratos militares, e, a despeito da gritaria sobre o complexo industrial-militar, identificado por alguns de nós já desće a I Guerra Mundial, duvido que venhamos no futuro próXimo adotar a solução de J. Kenneth Galbraith de socializar as indústrias de material bélico. Na verdade, o governo tem vendido arsenais e estaleiros. $O$ orçamento para o ano fiscal de 1970, na parte relativa à "execução da política externa e finanças", abrange assistência econômica, alimentos Para a paz, execução de politica exdos contribuições dos Estados UniOrganis as Nações Unidas e outros no exterior e intercâmbio; essas rubri- cas totalizam 3,8 bilhões de dólares, ou seja, menos de $2 \%$ do orçamento.

0 recrutamento continua. Três miIhões e meio de pessoas estão prestando serviço militar, dos quais mais de meio milhão estão na área de combate do Sudoeste Asiático. O funcionalismo civil no País e no exterior, não contando a CIA e incluindo o Departamento de Estado, a Agência para - Desenvolvimento Internacional (AID) e a Agência de Informaçōes dos Estados Unidos (USIA), ascende a mais de 50.000 4 Compare-se esta cifra com 80 pessoas que John Hay encontrou no Departamento de Estado em 1898 , ano que o Professor Graebner denominou "o ano de transição", em que passamos do isolacionismo para a participação nas questões mundiais. ${ }^{5}$

\section{O CRESCENTE VOLUME DE TRABALHO DO DEPARTAMENTO DE ESTADO}

O crescente volume de trabalho do Departamento de Estado e os problemas da organização daí decorrentes justificariam um simpósio à parte, embora nos documentos que se seguem sejam tratados aspectos importantes deses problemas. $O$ desmembramento dos grandes impérios coloniais e a subseqüente proliferação de Estados recém-independentes obrigaram $\circ \mathrm{De}$ partamento de Estado a manter missões diplomáticas em 120 paises, en-

3. Harold D. Lasswell, National Security and Individual Freedom (McGraw-Hill Book Company, Inc., New York, 1950).

4. The Budget in Brief: Fiscal Year 1970, Gabinete do Presidente dos Estados Unidos, Bureau of the Budget (U.S. Government Printing Office, 1969, Washington, D.C.)

5. Norman A. Graebner (editor), An Uncertain Tradition: American Secretaries of State in the 20th Century (McGraw-Hill Book Company, Inc., New York, 1961). 
quanto até 1961 esse total era de 99. A Subcomissão Jackson, criada pela Comissão para Operações Governamentais do Senado norte-americano, dramatizou essa escalada em um de seus relatórios:

"O crescimento do Departamento de Estado abateria até o Senhor Parkinson. As vésperas da entrada dos Estados Unidos na II Guerra Mundial, o Departamento empregava menos de 6.200 pessoas no Pais e no exterior. Atualmente, mais de 24.000 estão nas folhas de pagamento, com cerca de 7.000 servindo nos Estados Unidos e 17.000 no exterior, incluindo cerca de 10.000 cidadãos estrangeiros contratados localmente. A carga de trabalho do Departamento é enorme. Ele opera cerca de 274 postos no exterior, entre embaixadas, legações, missões especiais e repartiçöes consulares. Seu volume diário de tráfego telegráfico abrange cerca de 1.500 telegramas recebidos $e$... 1.500 expedidos, contendo mais de 400.000 palavras." 6

O crescimento da "diplomacia parlamentar" e da responsabilidade do Departamento pelas posiçöes assumidas por nossas missões na família de organismos das Nações Unidas introduziu uma nova dimensão de complexidade. Eu trabalhava no Gabinete de Harlan Cleveland em 1963, quando ele era Secretário de Estado Adjunto para Organismos Internacionais. Ele ligou seu interfone para ouvir uma intervenção nas Nações Unidas do falecido Embaixador Adlai E. Stevenson a fim de, como ele próprio comentou ironicamente, "o Departamento de Es- tado saber qual é nossa orientação hoje". (O Sr. Cleveland garantiu-me mais tarde que "a maior parte de nossa política nas Nações Unidas durante o tempo em que Stevenson estava em Nova lorque era desenvolvida para ele e por sua insistente solicitação por nossa repartição em Washington".). 0 Professor Burton M. Sapin relatou que em 1964 o Departamento era responsável pela coordenação da participação dos Estados Unidos em 540 reuniōes, com assuntos variando de controle populacional e usos pacíficos de energia nuclear a direito marítimo internacional e tráfico internacional de entorpecentes. ${ }^{7}$ Embora o Departamento ainda exerça uma dose preponderante de controle sobre nossas missões na área da manutenção da paz. sua autoridade é mais tênue em relação aos campos técnicos e especializados em que os outros órgãos, com competência específica, mas orientados para o âmbito interno, atuam com maior influência. O Manual do GOverno dos Estados Unidos, edição de $1968 / 69$, relaciona 16 departamentos $e$ agências que possuem secretários-adjuntos ou diretores de divisões para assuntos internacionais. Suas atividades muito lembram a observação ci-

6. The Secretary of State and the Ambas. sador. Henry M. Jackson (editor) (Freder sob A. Praeger, 1964), pág. 43, New York. on o título. de Jackson Subcommittee Papers Fro. the Conduct of American Foreign Policy, Fonda, derick A. Praeger vem publicando, para ven subalguns documentos importantes do organicommittee on National Security and Ormitzation $\theta$ de seu antecessor (Senate qual tee on Government Operations), do quano presidente o Senador Henry M. Jackson, tosdick. como chefe da sua assessoria Dorothy Fosdich

7. Burton M. Sapin, The Making of UnitiStates Foreign Policy (The Brookings ino de tution, 1966, Washington, D.C.). último so uma série de cinco importantes relatórios Unidos bre operaçōes e negócios dos Estados Brookings no estrangeiro, publicado por The Institution, mencionada no prefácio. 
nica do falecido Sir Austen Chamberlain de que "a diplomacia moderna é a arte de conduzir no exterior a poiltica doméstica". A diplomacia interdepartamental toma uma porção considerável do trabalho do Secretário de Estado e de seus auxiliares, embora se tenha feito progresso nessas relações e tenha sido reduzido o monitoramento excessivo do Departamento de Estado em conferências de técnicos o especialistas destituídas de implicafões politicas. O problema mais dificil, evidentemente, é o do relacionamento do Departamento de Estado com a Casa Branca e o Pentágono. Nos pronunciamentos públicos do Secretário de Estado e do Secretário de Defesa, seus papéis freqüentemente parecem estar trocados.

O Departamento de Estado enfrenta uma série de dilemas internos crônicos. Questöes de politica externa podem ser levantadas e até decididas em muitos setores e em muitos niveis. Todo ministério do exterior padece de um conflito inerente entre área e funSão. O Departamento de Estado tem, seguidamente, de conciliar suas poderosas divisões encarregadas de paises ou assuntos regionais com o trabalho das divisões substantivas e de serviço em geral. Uma chancelaria precisa também possuir uma grande "memória institucional". Pude observar que há uma freqüência excessiva de rota๑ão em altos cargos profissionais, a qual tende a diluir a função de "memória". Isso se aplica tanto ao serviSo público civil quanto aos funcionários do serviço diplomático. Não estou em condições de dizer quanto isso se deve ao Relatório Wriston. 8 O Departamento tem problemas profundos de administração de pessoal em relação aos quais os relatórios da Comissão Herter e seus assessores forneceram contribuições importantes. 90 Professor Sapin pediu atenção para uma dificuldade especial em um departamento cujo trabalho é predominantemente realizado por telegramas, qual seja, como a preocupação com - corrente e o imediato impede as considerações de planejamento a longo prazo. 10

\section{PODEM OS DIPLOMATAS}

ADMINISTRAR?

Existe ainda a questão sobre se funcionários do serviço diplomático, treinados para serem negociadores e empenhados em uma forma de corretagem política, caso por caso, podem prontamente assumir as novas funções que recaíram sobre eles, obrigando-os a se tornarem gerentes e administradores, envolvendo a coordenação de uma equipe de técnicos de muitos campos especializados. $O$ papel do serviço diplomático, especialmente no caso do embaixador, foi substancialmente modificado pelo tamanho e variedade de uma missão. ${ }^{11}$ Desde a

8. Henry M. Wriston, Toward a stronger Foreign Service. Relatório do Secretary of State's Public Committee on Personnel, Departiment of State Publication, 5458 (U.S. Government Printing Office, Washington, D.C., June 1954).

9. Personnel of the New Diplomacy. Herter Committee Reports. Frederick C. Mosher (editor). Carnegie Endowment for International Peace, Washington, D.C., 1962. Essa publicaçåo constitulu b relatório do Committee on Forelgn Affairs Personnel, constituido sob os auspicios do Carnegie Endowment for International Peace, solicitado pelo Secretário Dean Rusk. Esse trabalho foi continuado com uma série de seis estudos sobre problemas de pessoal para os negócios no estrangeiro, também publicados pelo Carnegie Endowment.

10. Sapin, op. cit. pág. 273.

11. Jacksion, op. clt., p. 62. 
carta de maio de 1961 do Presidente Kennedy aos Chefes de Missão, foiIhes atribuida, pelo menos no papel, a autoridade para coordenar e controlar todas as agências civis dos Estados Unidos nos paises respectivos. Charles Maechling Jr., em seu penetrante artigo sobre "Nossa Estrutura de Relações Exteriores: A Necessidade de Reforma", põe em dúvida que o embaixador tenha recebido poderes adequados. 12 o embaixador pode realmente ser o chefe ou apenas primus inter pares da "equipe no país"? Mesmo que ele tenha de ser informado, de uma forma geral, dos programas e atividades de sua bateria de técnicos e especialistas e tenha autoridade e influência suficientes para sustar atividades que ele considere nocivas às relações políticas, ele deve ter a sabedoria de não saber muito ou não intervir demais nas operações quotidianas altamente técnicas. No artigo acima referido, o Sr. Maechling chega a levantar dúvidas sobre se o diplomata, generalista, é capaz de nezados, como certos terrenos especiallfinanceirs questöes económicas e e ajuda externa. Um eneração técnica difícil surge no caso da Agência Central de Inteligência (CIA) e suas relações com o chefe da missão. Porém, outras áreas que revelam o alto conteúdo científico e tecnológico da diflomacia de objetivos múltiplos são as de pesquisa cientifica básica, energia atômica, controle do espaço interplanetário, oceanografia, comunicações e to sofisticado. controle de armamenno, em sua função adminador moderter interesses universals e dar estimu- lo e apolo e técnicos procedentes de vários campos dos quais ele próprio não pode e não precisa ser conhecedor profundo. Um número sempre maior de embaixadores se está adaptando a esses novos requisitos.

Diversas sugestöes têm sido formuladas no sentido de assessorar o Presidente e aliviar o pesado volume de trabalho do Secretário de Estado. 0 Sr. Maechling recomendou a criação de uma superpasta de Secretário para a Segurança Nacional, que presidiria um Conselho de Relações Exteriores, órgão permanente interdepartamental constituído no nivel de gabinete. Essa idéia muito se assemelha à sugestăo de criação de um Primeiro-Secretário com uma posição hierárquica acima do Gabinete, proposta por altas autoridades como os ex-Presidentes Hoover - Elsenhower e Governador Nelson Rockefeller. A meu ver, mais de acordo com a tradição histórica e as realidades politicas estão as propostas de reforçar a posição do Secretário de Estado e liberá-lo de forma que possa dedicar mais tempo à sua função do assessor principal do Presidente e $\mathrm{CO}^{-}$ ordenador dos programas de política exterior mais importantes do Governo como um todo. O relatório final da 18a Assembléía americana pediu a criação dos cargos de Secretário do Estado Substituto, três Subsecretários de Estado e uma série de outros responsáveis por assuntos regionals $(\theta$ das Naçöes Unidas), os quals "deveriam ter títulos e autoridades na proporçăo de suas relações com os governos e organizaçöes com os quals

12. Charles Maechiling, Jr., Our Foreign Attairs Establishment: the Need for Reform. Spring ginia Quarterly Review, Vol. 45, No. 2, Sprin 1969. 
tivessem de tratar". 13 A Comissão Herter propôs a criação do cargo de Subsecretário de Estado Executivo, hierarquicamente subordinado apenas ao Secretário e ao Subsecretário de Estado. 14

\section{A PRESIDENCIA}

\section{E A SECRETARIA DE ESTADO}

Presidente dos Estados Unidos é quem determina a política externa. A evolução de seu papel predominante nesses assuntos é descrita com clareza no livro do Professor Rowland Egger "O Presidente dos Estados Unidos". 15 Porém o número e a gravidade das decisões que têm de ser tomadas numa era de crise crônica tornaram seu volume de trabalho quase insuportável. O Presidente Nixon Provavelmente tem de tomar em uma Semana mals decisões que afetam questões de segurança nacional do que o Presidente Coolidge teria em um ano. Até a criação, em 1939, do Gabinete Executivo do Presidente, a Presidência năo dispunha de nenhum corpo institucionalizado de funcionários para auxiliar o Chefe de Estado no exercicio de suas atribuiçőes. Atualmente, o tamanho e as atividades operacionais do Gabinete Executivo, incluindo o pessoal da Casa Bran$\mathrm{Ca}$, teriam deixado estupefatos os membros da Comissão Presidencial sobre Gerência Administrativa (Comissảo Brownlow), que recomendara ao Presidente Franklin D. Roosevelt a criação daquele órgão.

${ }_{1947}^{A}$ Lei de Segurança Nacional, de Conselhom suas emendas, previa um nivel mino de Segurança Nacional em riores ministerial. As únicas leis antecriando conselhos ministeriais eram as que instituiram o Conselho de Defesa Nacional, em 1916, e o Conselho Nacional Assessor para Problemas Financeiros e Monetários Internacionais, previsto pela Lei de 1945 , que promulgou o Acordo de Bretton Woods, a qual fol abolida e superada pelas Ordens Executivas (decretos) nọs 11.269, de 4 de fevereiro de 1966, e 11.334, de 14 de março de 1967 , as quais, por sua vez, entre outras disposições, mudaram a última palavra de sua longa designação de "problemas" para "diretrizes". Nos trinta anos desde a criação do Gabinete Executivo, cada Presidente utilizou esses meios institucionalizados de auxilio de maneiras diferentes, dependendo de seu estilo de governar tanto quanto da situação mundial em diversas ocasiões, numa flexibilidade que é correta e adequada. Há, porém, um perigo considerável de que a ampliação do Gabinete Executivo do Presidente e do pessoal da Casa Branca, bem como sua intervenção em operações dia a dia, possam ter atualmente atingido um nivel de rendimentos decrescentes, a ponto de vir atrair para o escalão presidencial decisões em demasia e poder solapar a autoridade e a responsabilidade dos ministros. $\mathrm{Na}$ qualidade de antigo assessor da época em que o Gabinete Executivo fol criado, aferro-me ao conceito original de que ele deveria ser mantido pequeno, com um mínimo de responsabilidades

13. Don K. Prince (editor). The Secretary of state. Relatório da 18 th American Assembly, levada a efeito na Arden House, Columbia University, em outubro de 1960. (Englewood Cliffs, N. J.: Prentice Hall, 1960). 13.

14. Herter Committee Report, op. cit., pág.

15. The President of the United States. Rowland Egger. (McGraw-Hill Book Company, Inc., New York, 1967). 
operacionais do dia-a-dia, e se deveria saber que seus membros atuam em nome do Presidente, e não por sua própria conta. Este era o significado subentendido da "paixão pelo anonimato", mencionada no relatório da Comissão Brownlow. A natureza especial do relacionamento que deve necessariamente existir entre o Presidente e o Secretário de Estado fol expressada por Dean Acheson, ex-titular daquela pasta, em seu ensaio clássico sobre "O Presidente e o Secretário de Estado" e incluia a seguinte afirmação:

"... o relacionamento entre o Presidente, nosso Chefe de Estado e de Governo, e seu Secretário de Estado, seu principal assessor a agente executor na condução da política externa, é intensamente pessoal. O trabalho ao qual eles se devem dedicar conjuntamente será prejudicado na medida em que esse relacionamento venha a ser atenuado ou institucionalizado - ou "parkinsonizado". Precisamos redescobrir o individuo no Governo, não submergi-lo. Isto não significa que qualquer dos dois deva atuar, como protótipos de ambos o tem feito, independentemente do resto do governo ou, no caso de Secretário, independentemente do Departamento de Estado." 16

"SUI O AMBIENTE POLITICO DERIS" DA ADMINISTRAÇAO DIPLOMÁTICA DOS ESTADOS UNIDOS

As complexidades da administração de uma diplomacia de objetivos múltiplọs săo aumentadas em decorrência do ambiente político em que o Presi- dente e o Secretário de Estado têm de trabalhar. A autoridade compartida com o Congresso no terreno da condução das relaçöes exteriores é um sistema quase próprio deste País e, apesar de profundamente, como está, entranhado em nossa conceituação de instituições democráticas, apresenta problemas extraordinários ao Poder Executivo e é difícil de ser compreendido por outros países. 0 poder do Senado de rejeitar tratados pelo voto de um terço de seus membros e das duas Casas de rejeitar acordos assinados pelo Executivo por maioria simples seria suficiente para caracterizar o veto do Legislativo. A influência de um Senador Vandenberg para obter a ratificação da Carta das Nações Unidas ou a do Senador Henry Cabot Lodge I para derrotar a ratificação da Convenção da Liga das Nações, negociada pessoalmente pelo Presidente Wilson, são exemplos clássicos da autoridade exercida por um só senador. Reservas e emendas apresentam um problema quase tão grande quanto 0 dos vetos. A Emenda Hickenlooper às leis de ajuda externa parece ser por si mesma razoável e lógica. Entretanto, devido à sua rigidez, sua aplicaçüo literal no caso da República do Peru pode não só destruir nossas relações com aquele pais, como também prejudicar ainda mais nossa posiçäo em toda a América Latina.

Conquanto pesos e contrapesos e 0 debate público em relação às principais diretrizes de política externa fossem destinados a servir de salvaguardas contra $O$ uso de um poder executivo discricionário, as duas Casas do 16. Price, The Secretary of State op. eit.
pág. 27 . 
Congresso raramente conseguem manter-se nesses niveis elevados e deixar de intrometer-se em detalhes operacionais. O Congresso, suas comissões e subcomissões têm suas próprias divisões de jurisdição e estão sujeitos a pressões especiais e provincianas. Muito de nossa diplomacia de objetivos múltiplos é orientado para ações que envolvem dinheiro, de forma tal que não apenas as Comissões de Relações Exteriores do Senado e da Câmara se imiscuem nessas questões, mas também uma influência considerável é exercida pelas subcomissöes orçamentárias e seus poderosos presidentes. Os detalhes da legislação relacionada com ajuda externa, tanto militar como civil, assistência técnica, empréstimos para o exterior, comércio, tarifas, assuntos monetários, intercâmbio cultural, contribuiçōes para organismos internacionais, descendo à minúcia da estrutura e compeiência de agências no exterior e a categoria de seu pessoal, ficam freqüentemente ao sabor dos caprichos de uns poucos membros poderosos de subcomissões. Os estudos do Professor Joseph P. Harris e James A. Robinson lançaram muita luz sobre a influência do Congresso na formulaçäo de política externa. 17

\section{UM RAIO DE ESPERANÇA}

Concluo este catálogo excruciante das complexidades da condição de nossa diplomacia de objetivos múltiplos com uma nota esperançosa. Mesmo na questão da intervenção do Congresso, há uma melhoria grande desde a aprovação em 1924 da Lei Rogers, que criou um quadro de carreira do serviço exterior. Os senadores não mais controlam a nomeação de psssoal do serviço diplomático, de correio a embaixador. As confirmações na carreira são hoje quase tão automáticas quanto no caso de militares. Os estudos da Subcomissão. Jackson estão entre os mais notáveis documentos parlamentares de nossos tempos e nos trouxeram a um novo nivel de percepção e sofistificação com respeito à nossa máquina de política externa.

Porém, o mais surpreendente em toda essa mescla de perigo e complexidade retratada nesse documento é que o povo americano e suas instituições governamentais parecem ter faito mais do que apenas ir levandn". O ex-Embaixador e Subsecretário de Estado Foy D. Kohler conclui seu estudo sobre "Os Problemas que Enfrentamos" com as seguintes palavras:

"A despeito de nossas atuais dúvidas e confusões, sou otimisia. Quando olho para trás para o progresso que fizemos emergindo do isolacionismo nos anos 20 e 30 e nos ajustando ao papel mundial que a história nos impôs, não tenho dúvida de que a resposta americana ao desafio dos anos 70 será positiva." 18

E Harlan Cleveland, em seu corajoso ensaio "A Agonia do Exito", documentou a afirmação de que fizemos

17. The Advice and Consent of the Senate. Joseph P. Harris (University of California Press, Berkeley, 1953); Congressional Control Press, Berkeley, 1953 ); Congressional Conty, N. Y.: Anchor of Administration \& Company, Inc., 1965): Books, Doubleday \& Company, Making - A Study in Legislative Influence and Iniciative, James A. Robinson (Homewood, IIlinois. The Dorsey Press, 1967). pág. 1. 
melhor do que nosos rivais altamente organizados. 19

As previsões das autoridades não criam grandes esperanças de uma redução das tensões internacionais na década de 70 , embora elas as vejam assumindo novas formas que exigem modificações na atuação americana. Devemos ter cuidado com fórmulas ultra-simplificadas, panacéias e artificios que muito prometem para reduzir a variedade de nosos objetivos no exterior e a conseqüênte complexidade de nossa máquina administrativa diplomática $\theta$ aprender a viver com elas. A meu ver, isso não exclui a possibili- dade de um grau considerável de progresso na coordenaçăo de diretrizes $e$ operações de política externa, considerando-se nosso hábito nacional de auto-análise e nossa capacidade inventiva na administração. Muito depende de se conseguiremos encontrar meios para controlar o crescimento de gastos militares e dedicar uma proporção maior de nossos recursos nacionais aos programas civis urgentes de melhoria econômica e social no Pais e no exterior.

19. The Obligations of Power: American Diplomacy in the Search for Peace, Harlan Cleveland (Herper \& Row, chapter 3, New York, 1966). 